\title{
Desafios estratégicos na projeção do Brasil no Atlântico Sul
}

\author{
Murilo Gomes da Costa
}

Resumo: No presente trabalho,
buscar-se-áapresentarumaanálise
do cenário de projeção brasileira
para o Atlântico Sul, avaliando os
principais desafios estratégicos
advindos desta ação externa
brasileira, tendo como questões
centrais os projetos estratégicos
da Marinha do Brasil para a região
do Atlântico Sul, a presença de
potências extrarregionais, no
entorno estratégico brasileiro, e a
atuação brasileira na Antártica.

Palavras-chave: Atlântico Sul; Entorno Estratégico; Defesa; Estudos Estratégicos; Marinha do Brasil.

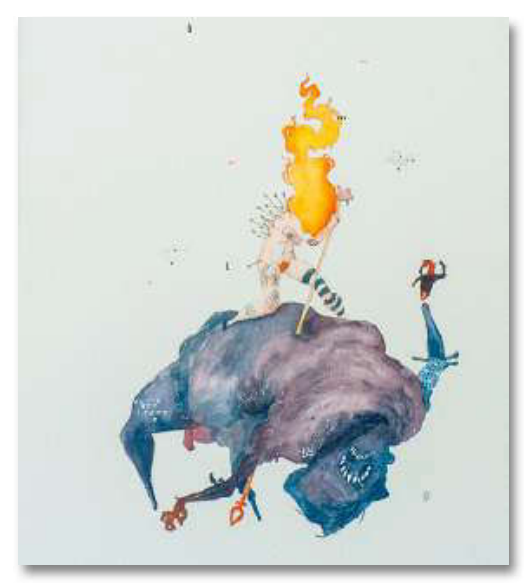

\section{Strategical Challenges for the Projection of Brazil in the South Atlantic}

\footnotetext{
Murilo Gomes da Costa

Mestrando em Ciência Política no Instituto de Estudos Sociais e Políticos da Universidade Estadual do Rio de Janeiro. Pesquisador do Laboratório de Análise Política Mundial.

murilogomes@iesp.uerj.br
}

Abstract: This paper presented an analysis of the Brazilian projection in the South Atlantic area, seeking to evaluate the main strategic challenges arising from this Brazilian external action, having as core issues the Brazilian Navy strategic projects regarding the South Atlantic Region, the potential presence of extraregional powers in the strategic surroundings of Brazil and the Brazilian action in Antarctica.

Keywords: South Atlantic; Strategic Surroundings; Defense; Strategic Studies; Brazilian Navy.

Recebido em: $\overline{28 \text { DE JULHO DE } 2015}$

Aprovado em: $13 \overline{\text { DE SETEMBRO DE } 2015}$

Tensões Mundiais | 323 
Murilo Gomes da Costa

\title{
1 INTRODUÇÃO
}

Analisando a importância do Atlântico Sul na formulação estratégica brasileira, o Brasil possui, na vertente atlântica, uma ampla gama de interesses que integram a dimensão do exercício da soberania, nas fronteiras marítimas. Dentre os principais objetivos brasileiros no Atlântico Sul, destacam-se: a manutenção da integridade do patrimônio nacional, que inclui, além do mar territorial e patrimonial, as águas, o solo e o subsolo da plataforma continental; a garantia de livre trânsito para o comércio exterior brasileiro; a exploração das potencialidades econômicas, que incluem recursos naturais e intercâmbio comercial; e a projeção que garanta a vigilância sobre as linhas de comunicação marítima que dão acesso ao território brasileiro (COUTO, 1999). Sendo o Brasil o país com um dos mais extensos litorais do mundo, tem-se, então, um interesse especial no tocante à paz e à segurança do Atlântico Sul. Este:

\begin{abstract}
[...] é geoestratégico para o sistema internacional desde que a América foi descoberta. Durante a Segunda Guerra Mundial sua importância se deu pelas rotas marítimas e aéreas que abasteciam os Aliados em bases militares na África e na Europa. Na Guerra Fria, consolidou-se esta ideia, à medida que os soviéticos exerciam influência e presença na África. Segundo os geopolíticos e estrategistas brasileiros, das décadas de 1960 e 1970, quando os inimigos invadissem o Atlântico sul-africano, para chegar ao da América do Sul não teriam maiores dificuldades. De acordo com estes estudiosos, civis e militares, resguardar os interesses brasileiros no Atlântico Sul justificaria o prolongamento da soberania brasileira para 200 milhas marítimas e o desenvolvimento autônomo de navios e submarinos convencionais e nucleares. (CORRÊA, 2013, p. 02).
\end{abstract}

Pela análise do Livro Branco da Defesa Nacional (LBDN), tornase possível a compreensão do Atlântico Sul como um "ambiente estratégico". Esse oceano possui áreas estratégicas relevantes como a "Garganta Atlântica", entre a costa do Nordeste brasileiro 
e a África ocidental, além de um espaço intercontinental de vital importância para o comércio mundial. As passagens ao sul, que ligam o Atlântico ao Pacífico, têm suma importância, pelo fato de se tornarem substitutas ao canal do Panamá. A rota do Cabo da Boa Esperança, unindo o Oceano Índico ao Atlântico Sul, finda por substituir alternativamente o de Suez, além de ser o acesso marítimo mais simples à própria Antártica.

Figura 1: Tonelagem exportada por via marítima, por rotas oceânicas (2011)

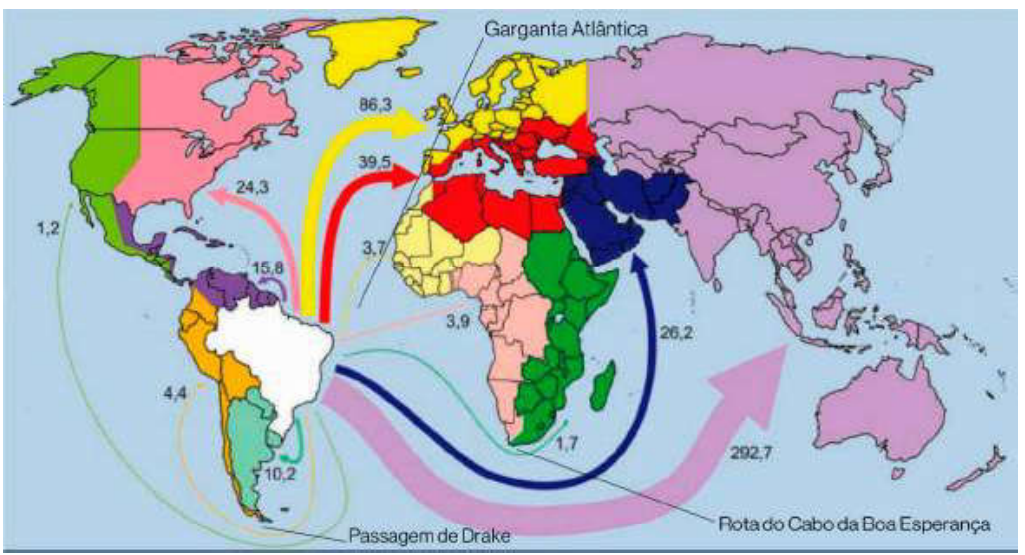

Fonte: Agência Nacional de Transportes Aquaviários (2015). Mapa adaptado com a identificação das rotas do Atlântico Sul

Assim sendo, o Brasil deixa transparecer a sua projeção ao Atlântico Sul, tendo em vista que os objetivos da Política Exterior brasileira se pautam na manutenção da soberania e da integridade territorial, assim como na contribuição para a estabilidade regional e na própria inserção internacional. Analisar-se-á aqui a inserção internacional do Brasil e seus desafios estratégicos, no tocante às ações no âmbito da Defesa, principalmente, por meio da Marinha, que consistem no emprego de mecanismos que possibilitem a "negação do uso do mar" às ameaças externas, o controle das áreas marítimas e na própria projeção do poder naval. 
Murilo Gomes da Costa

\section{O ATLÂNTICO SUL NO CONTEXTO DO SÉCULO XXI}

Com o final da Guerra Fria, o papel do Atlântico Sul, no contexto da segurança global, como parte da arquitetura de defesa do continente americano, perdeu o sentido que tinha no período anterior. Várias manobras conjuntas continuaram sendo realizadas, patrocinadas pelos EUA ou criadas de maneira bilateral ou multilateral entre Argentina, Brasil e Uruguai. No entanto, tiveram mais o caráter de fomento da confiança mútua que de preparo para lutar contra um inimigo comum.

Adentrando nos anos 2000, a questão da segurança regional no Atlântico Sul passou a ser retomada como pauta importante na política externa dos Estados banhados pelo oceano. De um lado, assiste-se à emergência da China como grande potência e seu crescente interesse pelos recursos naturais africanos. Nesse contexto, Porto de Oliveira (2008) ressalta que:

[...] a presença chinesa é a cada ano maior na África. Iniciou-se em 1989 e "manteve uma continuidade e aumento de interesses que hoje se desdobram em várias atividades, impulsionadaspeloextraordinário crescimento da economia chinesa. Calcula-se que existam cerca de 80 mil técnicos chineses trabalhando na África em obras de infraestrutura e em centros de excelência agrícola (PORTO DE OLIVEIRA, 2008, p. 28-30).

De outro lado, a reativação da quarta frota naval na América do Sul, pelos Estados Unidos, coincide com a descoberta de imensas jazidas de petróleo, na camada pré-sal da plataforma continental do Brasil.

É interessante destacar que foi recorrente, no começo dos anos 2000, um tema acerca da formação de uma aliança militar no Atlântico Sul. Segundo Romero (2010), uma das iniciativas foi a do então presidente da Venezuela, Hugo Chávez Frias, que deu início a uma proposta para que se criasse uma organização do Atlântico Sul, com a intenção de favorecer a multipolaridade. Segundo Chávez, a integração dos países sulamericanos deveria ser total, não podendo ser deixada de lado a face da integração no âmbito militar. Essa proposta teria como base principal as manobras conjuntas realizadas de maneira formal, tanto pelo Brasil como 
Desafios estratégicos na projeçÃo do Brasil no AtLÂntico Sul

pela Venezuela, no teatro do Atlântico e no Amazonas, mas que, segundo Chávez, deveria buscar incluir também os países africanos.

À época, em resposta, o ministro Nelson Jobim, ao apresentar a proposta do Conselho Sul Americano de Defesa, ressaltou que o Brasil não descartava a proposta do presidente Hugo Chávez e afirmava que a proposta apresentada por ele não divergia daquela exposta pelo presidente venezuelano. Em outras palavras, isso demonstrava que ambos almejavam o mesmo objetivo e estariam apenas utilizando diferentes linguagens para dizer basicamente a mesma coisa (RABELO, 2008).

Um importante acontecimento - que teve grande impacto na inflexão dos rumos do desenvolvimento em direção ao Atlântico Sul - foi a descoberta das novas jazidas na Bacia de Campos e, principalmente, os promissores campos nas águas profundas da Bacia de Santos (o Pré-sal). Com isso, o país tornou-se autossuficiente em petróleo, no início dos anos 2000, e hoje quase $90 \%$ da produção provém da exploração offshore. Estudos de potencialidade indicam que, após a entrada em operação dos campos do Pré-sal, haverá condições de produzir excedentes e o país poderá tornar-se importante exportador de petróleo, de gás natural e dos seus derivados (COSTA, 2012).

Figura 02: Província Petrolífera do Pré-Sal

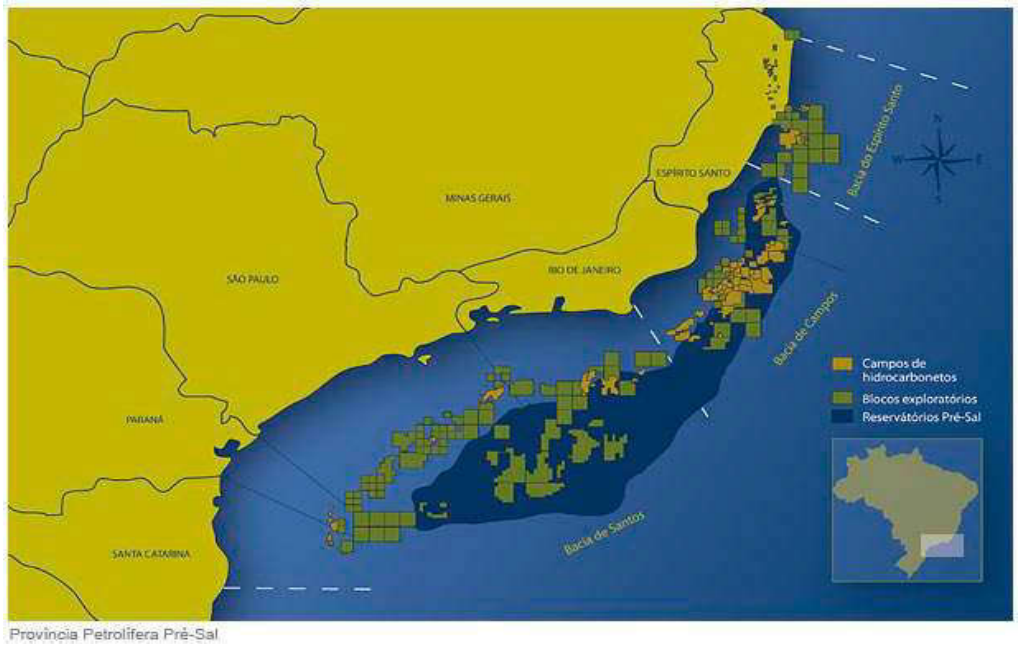

Fonte: Um desafio... (2016) 
Murilo Gomes da Costa

Convém ressaltartambém a construção do conceito de Amazônia Azul. Geograficamente, ela corresponde a aproximadamente metade da superfície do Brasil (cerca de 4,5 milhões de $\mathrm{km}^{2}$ ), essa extensa área marítima atlântica, ao longo da costa brasileira, compara-se à "Amazônia Verde", não só pela dimensão, mas também pela biodiversidade, riquezas e pelo esforço a ela dedicado por pesquisadores, para a compreensão de sua magnitude, nos mais diversos campos da ciência e da tecnologia. A origem deste conceito advém do ano de 2004, quando foi:

[...] empregada originalmente pelo Comandante da Marinha (CM), em Tendências/Debates: A outra Amazônia, na Folha de São Paulo, em 2004, a expressão "Amazônia Azul" enseja um amplo horizonte de valores, recursos e iniciativas. A partir dessa ocasião a Marinha passou a adotar esse conceito, seja como objetivo educacional ou cultural, seja como objetivo político. O objetivo maior da Marinha é despertar na sociedade Brasileira uma mentalidade marítima consistente, coerente com as dimensões e importância dessa região para o Brasil. O uso dessa ideia força nessa última década e sua imediata aceitação por parte da população apontam para um êxito dessa empreitada (MIGUEL, 2013, p. 25).

O maior ponto de inflexão da relação que o Brasil desenvolveu com o Atlântico Sul, no século XXI, advém do desenvolvimento da política externa do governo de Luís Inácio Lula da Silva, com seu foco no Sul Global. Esta política externa demonstrou visar a uma diplomacia que se propusesse a consolidar a condição de "ator global" do Brasil, no sistema internacional.

Esse esforço, conceitualmente marcado pelo pensamento nacionalista, acabou por fortalecer a posição internacional do Brasil, a fim de superar as vulnerabilidades externas que limitavam seu pleno desenvolvimento. Por esse viés, a superação dos entraves gerados pela assimetria sistêmica da globalização seria viável pelo aprofundamento da cooperação Sul-Sul, motivo pelo qual ações, como a política africana, seriam retomadas em novos moldes.

Durante o primeiro discurso proferido como presidente, Lula enfatizou a importância de fortalecer esses laços históricos com o 
Desafios estratégicos na projeçÃo do Brasil no AtLÂntico Sul

continente africano e a força de vontade para ajudar a desenvolver o grande potencial da África. Além disso, é importante notar que o seu discurso:

[...] reintroduziu a política brasileira na outra margem do Atlântico, a qual passou a ser uma das prioridades para o governo do Brasil. Durante os oito anos de governo de Lula houve 12 missões chegadas por ele, nas quais o presidente foi acompanhado por comitivas de empresários, assinalando o interesse real em ampliar os negócios na região. As missões também auxiliaram na aproximação entre os países do Mercosul e os africanos. Celso Amorim, Ministro das Relações Exteriores do governo Lula, fez 67 visitas à África, em 34 países diferentes. Amorim e Samuel Pinheiro Guimarães - secretário geral do MRE - deram prioridade ao continente africano no que diz respeito à formação de diplomatas, além da reestruturação do Departamento para assuntos africanos e do Oriente Médio, sendo criado um Departamento para Assuntos Africanos, com três divisões e seu próprio orçamento. Ainda, foram abertas 17 novas embaixadas (BARBOSA; PEREIRA, 2012, p.67).

Dessa maneira, a recuperação, no governo Lula, da política africana permitiu ao Brasil certa participação na fronteira atlântica do Brasil e proveu funcionalidade aos interesses brasileiros, além de certos valores à projeção internacional do país. A África recebe investimento brasileiro, como os do Banco Nacional de Desenvolvimento Econômico e Social (BNDES), e empresas internacionalizadas nacionais estão presentes em solo africano, como empreiteiras, uma grande mineradora e uma petrolífera.

No caso de Angola, a presença do investimento direto brasileiro é apreciada e resulta em percentual importante: chega a quase $90 \%$ do investimento externo global, nos anos de 2013 e 2014. Chegam à África jovens engenheiros e trabalhadores de todo o Brasil, mesmo de pequenas cidades, que hoje trabalham em empresas brasileiras e internacionais, em países que viraram canteiros de obra, como Angola. O próprio trânsito de pessoas se tornou mais visível. Há mais brasileiros na África, nesta quadra histórica, e já começam esses brasileiros a conhecer e admirar mais as realidades do outro lado do Atlântico Sul (SARAIVA, 2012). 
Murilo Gomes da Costa

O governo Lula ainda demonstrou uma forte preocupação em mudar a perspectiva sobre o papel de defesa para o país e a necessidade de investimento nas Forças Armadas, como foi desenvolvido na Estratégia de Defesa Nacional (EDN). Na verdade, a EDN, às vezes, é chamada de Programa de Aceleração do Crescimento (PAC) militar, em comparação com o PAC econômico que Lula lançou, no seu segundo mandato, para impulsionar o crescimento econômico do Brasil. Trata-se de ter a capacidade de defender o Brasil, do poder de dissuasão, de cuidar da soberania do país na terra e no mar. Em particular, o Brasil começou a ajudar alguns países africanos a melhorar os seus sistemas de defesa. Na maioria dos casos, o Brasil prestou auxílio para a formação de militares profissionais.

Em 2010, o então ministro da Defesa, Jobim, também declarou que a Marinha do Brasil daria assistência a países da África Ocidental quanto à confecção de mapas da Plataforma Continental e delimitação das fronteiras de suas plataformas. O objetivo é conseguir manter o Atlântico Sul, sob o controle soberano dos países de ambos os lados desse oceano, na medida do possível. (WIESEBRON, 2013).

\section{AÇÕES NO ÂMBITO DA MARINHA DO BRASIL E SUAS IMPLICAÇÕES PARA A DEFESA NACIONAL}

Para que fosse possível concretizar uma efetiva projeção para o Atlântico Sul, diversas iniciativas foram realizadas para engendrar uma atuação brasileira efetiva, neste importante entorno estratégico brasileiro. Serão apresentados, nesta seção, os principais projetos estratégicos da Marinha do Brasil, que vêm sendo desenvolvidos em conformidade aos anseios da EDN de uma inserção maior do Brasil na região do Atlântico Sul, levando em conta não só as proximidades da área, no caso a Amazônia Azul, como também a ação brasileira em face aos países lindeiros do continente africano, bem como a região antártica.

O intento de se projetar para o Atlântico Sul sustenta-se, principalmente, no fato de o Brasil possuir uma das mais equipadas marinhas da região do Atlântico Sul, principalmente, por ter um 
Desafios estratégicos na Projeção do Brasil no AtlÂntico Sul

extenso território marítimo. O Atlântico Sul, como já citado, possui uma relevância econômica, social e militar, que, comparavelmente, só a Amazônia Brasileira tem. Dessa maneira, tendo como base a EDN, no que tange ao setor marítimo, os principais pontos ressaltados como objetivos da Marinha são a negação do uso do mar, o controle de áreas marítimas e a projeção de poder.

Os projetos estratégicos da Marinha demonstram que as recomendações da EDN já começam a tomar um rumo (e muitos projetos já estão finalizados ou sendo encaminhados). Dentre os principais projetos, destacam-se o Programa Nuclear da Marinha (PNM), a construção do Núcleo do Poder Naval e o Sistema de Gerenciamento da Amazônia Azul (SisGAAz). ${ }^{1}$

O Programa Nuclear da Marinha, iniciado em 1979, divide-se em dois projetos maiores: o domínio do Ciclo do Combustível Nuclear e o Laboratório de Geração Núclero-Elétrica (Labgene). O Brasil já domina todo o ciclo de produção do combustível nuclear, usando material nacional. Ademais, a Marinha inaugurou, no início de 2012, a Unidade Piloto Hexafluoreto de Urâneo (Usexa), que é a última etapa para o domínio pleno desse ciclo. Esse laboratório possui o propósito de desenvolver a capacidade tecnológica para o projeto, construção, operação e manutenção do reator nuclear do tipo Pressurizes Water Reactor (PWR), que será empregado na propulsão do primeiro submarino Nuclear (SN-BR) a ser construído no Brasil.

Esse programa concederá ao Brasil a capacidade para operação de plantas núcleo-elétricas de tecnologia nacional. A energia poderá ser usada tanto nos fins civis-urbanos, quanto na propulsão de meios navais. (MARINHA..., 2011).

Em relação ao Núcleo do Poder Naval, este almeja modernizar e ampliar a capacidade operacional da Marinha brasileira. O plano, inicialmente elaborado pela EDN, se estrutura na aquisição

1 "Amazônia Azul" é um conceito usado pela Marinha brasileira, que almeja contribuir para o desenvolvimento da cultura marítima brasileira, divulgando a importância do mar para o País; "O principal objetivo seria o de ampliar, em todos os níveis, a divulgação do conceito "Amazônia Azul", com foco em suas vertentes econômica, ambiental, científica e da soberania, enfatizando os aspectos de natureza política e legal". (MARINHA..., 2011, p. 01) 
Murilo Gomes da Costa

e distribuição de material, navios e instalações. Esse núcleo é formado por programas que têm o propósito de expandir e modernizar a Força Naval. Dentre eles está o desenvolvimento de submarinos convencionais e, também, os de propulsão nuclear (Prosub), além da construção de um estaleiro de base naval.

Ademais, está prevista a construção de um Navio-Aeródromo (Pronae), do Navio-Anfíbio (Pronag), de meios de Superfície (Prosuper) e a produção de navios-patrulha de 500 toneladas, além das corvetas Classe Barroso. Além disso, já foi criada a Unidade de Fabricação de Estruturas Metálicas (UFEM), que integra uma parte do processo do ProSub. A previsão é que o primeiro submarino nuclear fique pronto em 2017 (MARINHA..., 2011).

A relevância de um submarino com propulsão nuclear reside no fato de ele permitir uma maior proteção da costa brasileira, já que ele consegue um maior sucesso na "negação do uso do mar", dado ter um tempo de submersão muito prolongado e usar a energia nuclear. A Marinha do Brasil também enseja o lado social, que será trabalhado em paralelo à construção da Base Naval de Itaguaí, no Rio de Janeiro. Esses programas estimularão a formação de mão-de-obra local qualificada, além de estimular a produção da economia local.

É importante relevar também que o nosso ambiente geoestratégico é deveras complexo. No entorno litorâneo brasileiro, por exemplo, há um cordão de ilhas de posse do Reino Unido, com destaque para a ilha de Ascensão, que serve, há algumas décadas, de base para as operações militares dos Estados Unidos e do Reino Unido no Atlântico Sul, na América do Sul e na África.

Por fim, o SisGAAz se configura num conjunto de sistemas que tem como objetivo ampliar a capacidade de monitoramento e controle das águas jurisdicionais e das regiões de busca e salvamento, sob responsabilidade do Brasil.

A "Amazônia Azul" consiste numa área de aproximadamente 4,5 milhões de quilômetros, correspondente, em tamanho, à Amazônia terrestre. Esse projeto utiliza-se de satélites, radares e equipamentos de sensoriamento submarino, a fim de monitorar o mar territorial brasileiro. Tal estrutura comporá uma rede de informação e de apoio à decisão. 
A importância estratégica do SisGAAz se dá no fato dela atender às diretrizes da EDN, já que ela se dá sob a égide do trinômio "monitoramento/controle", "mobilidade" e "presença". Ou seja, sob esse aspecto, o sistema aumenta a capacidade de resposta aos eventos que representam uma ameaça para a vida humana, a segurança, a economia e o meio ambiente.

Os possíveis benefícios desse sistema seriam advindos do fato de ele empregar civis e militares, além de ser útil no combate às novas ameaças, tal qual o tráfico ilegal de entorpecentes, e na própria possibilidade de operação com outros sistemas, como o Sistema de Vigilância de Fronteiras (Sisfron) e o Sistema de Defesa Aérea Brasileira (SDAB) (BRASIL, 2013). No infográfico abaixo, é possível compreender a sistematização e o funcionamento integrado do SisGAAz:

Figura 03: O Sistema de Gerenciamento da Amazônia Azul

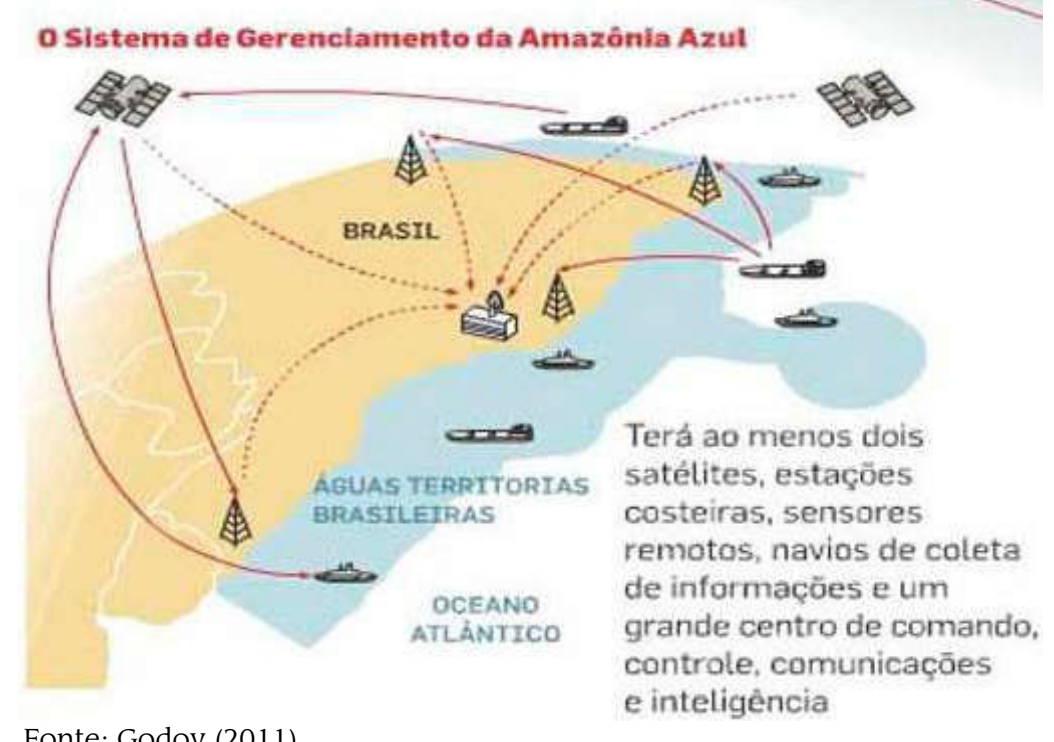

Fonte: Godoy (2011)

É importante abordar aqui também algumas questões acerca das fronteiras marítimas brasileiras. O Brasil vem pleiteando, junto à Comissão de Limites da Plataforma Continental (CLPC) da 
Murilo Gomes da Costa

Convenção das Nações Unidas sobre o Direito do Mar (CNUDM), a extensão dos limites de sua Plataforma Continental, além das 200 milhas náuticas $(370 \mathrm{~km})$, correspondente a uma área de 963 mil $\mathrm{km}^{2}$.

Desde agosto de 2004, os representantes brasileiros apresentaram uma proposta à CLPC da ONU, contendo esse pleito de uma área, além das duzentas milhas da Zona Econômica Exclusiva (ZEE), com aproximadamente $950.000 \mathrm{~km}^{2}$. No entanto:

\begin{abstract}
As avaliações da CLPC se deram ao longo de três anos (2004-2007). Pouco antes da decisão final da CLPC, a delegação brasileira, composta por diplomatas e especialistas da Marinha do Brasil, da Petrobras e da Comunidade Científica, fizeram a apresentação contendo seus argumentos científicos e técnicos, que seria utilizado como base para a proposição. Após as devidas deliberações, a CLPC formalizou sua decisão ao Governo brasileiro sob a forma de recomendações, segundo as quais o Brasil poderá apresentar nova proposta que, sendo aceita, permitirá a incorporação de, no mínimo, 700.000 Km2, e, no máximo, 950.000 $\mathrm{km}^{2}$, em valores aproximados. Essa área se distribui ao longo da costa, principalmente nas regiões Norte, Sudeste e Sul, a partir do limite das 200 milhas até o bordo exterior da margem continental, nas regiões em que as características do prolongamento do território nacional se enquadram nas disposições da Convenção das Nações Unidas sobre o Direito do Mar (ADESG, 2011, p. 03).
\end{abstract}

Em síntese, o próximo momento deste processo seria, então, a avaliação da Comissão Interministerial para os Recursos do Mar (CIRM) acerca da decisão da CLPC, a fim de subsidiar a decisão do Governo brasileiro, que poderá ser o envio de uma nova proposta, aceitando as recomendações formuladas, o prosseguimento na defesa do pedido inicial, ou, ainda, uma nova linha de ação que venha a ser delineada nos estudos, ainda em andamento. De qualquer maneira, a grande relevância, reside justamente no fato de que estão sendo construídas as bases para um traçado definitivo da fronteira marítima do País, na Amazônia Azul. 


\section{INICIATIVAS BRASILEIRAS PARA UMA ATUAÇÃO NA ANTÁRTICA}

Torna-se importante apontar também as iniciativas da Marinha do Brasil, no que se refere à Antártica. Primeiramente, é importante compreender que a Antártica é geograficamente um continente 1,6 vezes maior do que o Brasil e que também possui um elevado potencial de riquezas minerais ainda não exploradas. Além disso, ela é uma região de crucial importância para duas importantes rotas de navegação para o comércio marítimo internacional a do Cabo e a do estreito de Drakeé, sendo assim fundamental para o equilíbrio ambiental do planeta, em especial dos países do hemisfério sul (MATTOS, 1996).

O Brasil assinou, em maio de 1975, o Tratado da Antártica, passando a integrá-lo como membro aderente, sem direito a voto nas deliberações. No segundo semestre desse mesmo ano, criou-se um grupo de trabalho interministerial, sob coordenação do Ministro das Relações Exteriores, com o propósito de reunir subsídios para formulação de uma política nacional relativa ao assunto e propor as primeiras medidas concretas para a atuação brasileira na Antártica. O grupo de trabalho, que contava com a participação de oficiais hidrógrafos, proporcionou a criação dos fundamentos da política antártica brasileira (MATTOS, 1996).

No início da década de sessenta, oficiais hidrógrafos passaram a atuar como observadores, em expedições chilenas à Antártica. Posteriormente, oficiais de outras especialidades também acompanharam operações inglesas, argentinas, russas e alemães, além das chilenas. A partir de 1981, o Governo brasileiro decide enviar uma expedição à Antártica, para isso, adquiriu-se da Dinamarca um navio polar, Thala Dan, que recebeu, no Brasil, a classificação de Navio de Apoio Oceanográfico e o nome de Barão de Teffé (MARINHA..., 2015).

Em 1983, o Brasil inaugurou a Estação Antártica Comandante Ferraz e foi admitido como Membro Consultivo do Tratado da Antártida. Desde então, e em consonância com o Tratado da Antártida e com o Protocolo de Madri, a presença brasileira naquele continente tem se orientado pela busca da compreensão dos fenômenos naturais daquele continente e de sua repercussão 
Murilo Gomes da Costa

sobre o planeta, em particular sobre o território nacional e a região em que estamos mais diretamente inseridos: a América do Sul.

Vale ressaltar também que as atividades do Programa Antártico Brasileiro (PROANTAR) são coordenadas por um órgão colegiado, a Comissão Interministerial para os Recursos do Mar, presidido pelo Comandante da Marinha, e se realizam por intermédio de vários ministérios e órgãos de pesquisa. ${ }^{2}$ Esse conjunto de instituições, que perfaz o Sistema Antártico Brasileiro, tem ainda o amparo da Frente Parlamentar de Apoio ao Programa Antártico Brasileiro $^{3}$ (AMORIM, 2014).

Graças à ação conjugada desses atores, o Programa tem tido importantes resultados: expressiva produção científica; formação de novas gerações de pesquisadores antárticos; aquisição de experiência operacional em ambiente glacial e de clima adverso; e desenvolvimento de complexa atividade logística em área remota. Para além da ampla gama de cientistas e universitários brasileiros presentes na Antártida, a própria Marinha do Brasil tem participado de importantes pesquisas, como interação oceano-atmosfera e desenvolvimento de tecnologias de construção em locais remotos (AMORIM, 2014).

\section{PRESENÇA DE POTÊNCIAS EXTRARREGIONAIS NO ATLÂNTICO SUL}

É imprescindível analisar também uma das principais motivações para que todas essas ações e projetos venham sendo realizados, que é a presença de potências extrarregionais no Atlântico Sul, visto que elas atuam diretamente em uma área estratégica brasileira. E, também, pelo fato de que há um forte

\footnotetext{
2 O PROANTAR apoia a execução de pesquisas que tenham por objetivo ampliar os conhecimentos dos fenômenos antárticos e suas influências sobre questões de relevância global e regional. Sua implementação logística está a cargo da Comissão Interministerial para os Recursos do Mar (CIRM), vinculada ao Comando da Marinha (Ministério da Defesa - MD, CNPQ, 2013).

3 A "Frente Parlamentar de Apoio ao Programa Antártico Brasileiro" foi criada em 2007 e congrega Deputados e Senadores em torno do objetivo de auxiliar no levantamento de recursos necessários ao desenvolvimento do Proantar. (FERREIRA, 2009).
}

336 | Tensões Mundiais, Fortaleza, v. 21, N. 22, P. 323-346, 2016 
controle sobre o Atlântico Sul exercido pelas grandes potências. Assim, os países costeiros, sejam da América do Sul ou da África, não logram estabelecer sua presença efetiva, assegurar seus interesses ou possuir autoridade sobre o Oceano. Desta forma, é importante entender como atuam a França, o Reino Unido e os Estados Unidos nesse ambiente.

De acordo com Reis (2011), a área estratégica brasileira precisa ser ampliada, pelo fato de que:

$$
\begin{aligned}
& \text { Ninguém faz defesa somente dentro da } \\
& \text { própria área territorial. É preciso pensar } \\
& \text { sempre em se defender longe do litoral, a } \\
& \text { fim de não atrair a ameaça para dentro do } \\
& \text { próprio território. [...] busca-se obter um } \\
& \text { tempo de resposta em níveis adequados, } \\
& \text { ainda mais hoje, quando os meios ofertados } \\
& \text { pelo desenvolvimento tecnológico encurtam } \\
& \text { distancias e os períodos temporais ao } \\
& \text { processo de tomada de decisão (REIS, 2011, } \\
& \text { p.70). }
\end{aligned}
$$

É interessante notar, conforme afirma Neves (2015), que os Estados Unidos vêm buscando diminuir a sua elevada dependência de petróleo do Oriente Médio, por meio da procura de outras fontes fornecedoras, sendo este um dos pontos principais da sua visão estratégica de longo prazo. Dessa maneira, segundo Reis (2011), este movimento de procura por novas fontes de petróleo estaria imbricado com a ativação da $4^{\circ}$ Frota, que não teria relação somente com a área de atuação do Comando Sul dos Estados Unidos. Dessa maneira, outro motivo aparente para a criação da Quarta Frota seria justamente o crescimento espantoso da exploração de hidrocarbonetos na costa do continente africano, principalmente no Golfo da Guiné, para alimentar a sede de gás e petróleo do mundo.

Frente a tal cenário, a presença estadunidense no Atlântico Sul se dá em três ações: o restabelecimento da IV Frota dos EUA, em julho de 2008, o fortalecimento do United States Southern Command (Southcom) e a criação do Africom, em outubro de 2008. Pela primeira vez, os EUA possuem uma estrutura militar que conta com seis Comandos Unificados Combatentes e seis frotas no globo. De acordo com as ações mencionadas acima, percebe-se 
Murilo Gomes da Costa

que os EUA completaram o estabelecimento de sua capacidade global de projeção de forças (BATTAGLINO, 2009).

A IV Frota é responsável pela segurança do Atlântico Sul, comportando os navios, submarinos e aeronaves que fazem a defesa da área sob responsabilidade do Southcom (MACLAY et alli, 2009). Consequentemente, a IV Frota trabalha conjuntamente com o Southcom e é responsável pela região da América Latina. Segundo Maclay et alli (2009), o objetivo oficial declarado da IV Frota é estreitar a cooperação e a parceria dos países da região, por meio de cinco missões: apoio a operações de manutenção de paz, assistência humanitária, auxílio a desastres, exercícios marítimos tradicionais e apoio a operações antidroga.

Adicionalmente, os EUA afirmam em seus documentos que a ascensão social e econômica brasileira, nos últimos anos, também pode vir a apresentar um desafio aos interesses estadunidenses. Finalmente, a ascensão daquilo que é chamado pelos Estados Unidos de "neopopulismo radical", como a emergência de governos de esquerda na América do Sul, também é considerada uma afronta à hegemonia estadunidense (MACLAY et alli, 2009).

Em suma, nota-se que, dos dois lados do Atlântico Sul, os EUA vêm fortalecendo sua presença militar na última década. O crescimento da importância estratégica do Oceano para a potência norte-americana fez com que este adotasse uma abordagem que, muitas vezes, choca-se com as perspectivas dos países costeiros.

No caso da Grã-Bretanha, o Atlântico Sul exerceu papel central para o estabelecimento do império ultramarino britânico. Assim, para a consecução deste objetivo, os estrategistas da Marinha Inglesa acreditavam que o Reino Unido deveria controlar rotas marítimas estratégicas (PENHA, 2011). Deste modo, ao longo de sua história, o Reino Unido estabeleceu uma presença territorial destacada na Bacia do Atlântico Sul, o que lhe confere capacidade estratégica singular atualmente, superior, inclusive, aos próprios países costeiros. Adicionalmente, vale destacar que o Reino Unido possui uma das marinhas mais bem equipadas do mundo. De acordo com o International Institute For Strategic Studies (IISS, 2013), a Marinha Britânica dispõe de um ativo de 32 mil homens, além de possuir uma frota com onze submarinos, sendo quatro 
deles nucleares, além de conter cinco destróieres, treze fragatas, 22 navios de patrulha e defesa costeira, 41 navios anfíbios, 16 navios destinados a guerra de minas e 10 navios para logística e suporte. Somado a isso, apresenta também dois porta-aviões, que estão em fase de construção e devem ser comissionados a partir de 2017, o que tende a exacerbar a presença britânica na bacia sul atlântica. O Reino Unido possui também forças, atuando no Atlântico Sul, especialmente nas ilhas Malvinas, onde há cerca de 1500 soldados permanentes, um navio patrulha, um navio escolta e eventualmente um submarino em Ascensão e Serra Leoa. Além disso, há também um destróier em estado de patrulha permanente no Atlântico Sul (GOMES GUIMARÃES, 2015).

Figura 3: Mapa referente aos territórios ultramarinos britânicos, localizados no Atlântico Sul

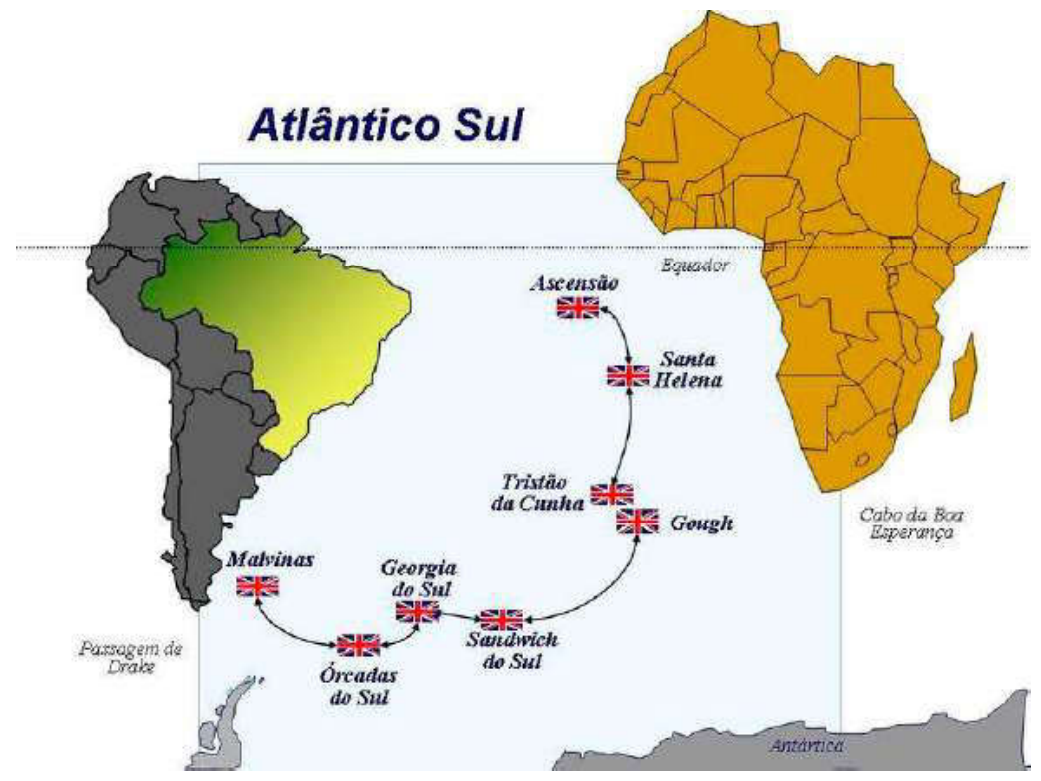

Fonte: Fórum Defesa Brasil (2015)

Ainda que em menor proporção, quando comparada aos EUA e à Grã-Bretanha, a presença francesa no Atlântico Sul é bastante significativa. Como demonstrado, a potência europeia mostra 
Murilo Gomes da Costa

interesse nos dois lados do Atlântico: na costa sulamericana, a materialização disto se deu na Guerra da Lagosta, iniciada em 1961, e na posse até hoje de um território ultramarino no Oceano, a Guiana Francesa. É na costa africana, entretanto, que ficam claros os interesses franceses pelo Oceano. Desde que foram concedidas as independências aos Estados africanos que tinham a França como metrópole, esta busca assegurar sua influência por diversos meios e instrumentos sobre os países nascentes. Desde então, houve a formação daquilo que Verschave (2004, p. 05) denominou de Françafrique, uma "rede através da qual foram estabelecidos diversos sistemas de dominação, com o objetivo de manter a dependência dos países africanos em relação à antiga metrópole" (OLIVEIRA; SILVA; PALUDO, 2013, p.164).

Ainda segundo Verschave (2004), os principais objetivos da atuação francesa no continente africano eram a obtenção de Estados-clientes e a aquisição de matérias-primas. Uma das principais materializações da dependência das ex-colônias em relação à França foi a criação da Comunidade Financeira Africana, ou Zona do Franco, que adota o Franco CFA como moeda.

Além dos interesses e da influência francesa na África, a França se faz presente no Atlântico Sul, em função da posse da Guiana Francesa. O território foi colônia francesa até 1946, quando se tornou um departamento ultramarino francês. A principal e a mais dinâmica atividade no departamento é a presença do Centro Espacial de Kourou, o centro de lançamentos da Agência Espacial Europeia. Ainda, a importância da Guiana Francesa é destacada em função da ratificação francesa da Convenção das Nações Unidas sobre o Direito do Mar (UNCLOS), o que lhe dá o direito de exploração dos recursos marítimos da região.

Ainda que exista a presença extrarregional dessas potências e mesmo frente à militarização de origem externa ao Atlântico Sul, os países situados nas margens do oceano ainda não chegaram a produzir declarações ou resoluções especificamente contrárias à presença estrangeira na região, exceto quando se trata de zonas disputadas, como as Ilhas Malvinas, ou do caso do AFRICOM, sobre o qual os países africanos sofreram maior constrangimento e acabaram tendo de se pronunciar. 
Entretanto, os países que pertencem geograficamente ao Atlântico Sul têm reiterado o interesse em protagonizar e resolver os problemas da região por si sós, através da cooperação. Ou seja, é esse tipo de ação internacional prévia que tem sido construída no que tange à militarização do oceano, uma reação indireta à ingerência extrarregional na área.

\section{CONCLUSÃO}

Diante do exposto, compreende-se que o Brasil valoriza o espaço comum propiciado pelo Atlântico Sul pelo grande potencial que encerra para o desenvolvimento socioeconômico dos países costeiros, a ser alcançado por meio da cooperação entre os Estados-membros. Busca, da mesma forma, sua consolidação como zona de paz e cooperação, livre de armas nucleares ou de quaisquer armas de destruição em massa. Para tal, o caminho a ser seguido parece tomar uma forma cada vez mais consistente.

O Brasil possui uma vantagem que poucos países têm, que é o fato de ter suas "fronteiras terrestres pacíficas", devido à sua boa relação com os Estados vizinhos, além de possuir uma economia que despontou de forma exponencial, configurando-se em uma verdadeira potência econômica.

As políticas diplomáticas e de defesa demonstram a maturidade do pensamento estratégico dos representantes brasileiros. Todavia, um papel fundamental ainda precisa ser exercido. Os estudos de Defesa Nacional e sua relevância, tanto para fins civis, como militares, necessitam ser passados desde a educação básica, para que o Brasil, do menor para o maior âmbito, possa pensar estrategicamente. Isso porque, olhando para o nosso vasto litoral, é notável que:

O Brasil dispõe de uma verdadeira 'Amazônia Azul', em relação à qual, sem dúvida, exerce direitos, mas tem também obrigações de conhecê-la e explorá-la economicamente, de forma racional e sustentável. Consequentemente, as riquezas incalculáveis desse espaço marinho sob jurisdição nacional exigem também um Poder Naval capaz de protegê-las (CARVALHO, 2004, p. 01). 
Murilo Gomes da Costa

Vale ressaltar também, conforme discute Saraiva (2012), que a política africana de Lula serviu para reforçar a ideia de que o Brasil ainda tem um projeto cooperativo Sul-Sul, em bases modernas, a engendrar alguma liderança nas novas rodadas de negociação de temas globais, na reformulação do Conselho de Segurança da Organização das Nações Unidas, na busca de parcerias estratégicas ao Sul hierárquico.

Portanto, o controle do Atlântico Sul pelo Brasil, como se argumenta, pode ser obtido, através da cooperação com seus vizinhos sulamericanos, bem como tal cooperação pode ser encontrada nos países africanos lusófonos. Percebe-se, portanto, que a cooperação com tais países da costa oeste africana é de extrema relevância, não sendo suficiente apenas dispor de equipamentos adequados.

Assim sendo, é de suma importância entender que a ascensão do Sul global e o seu potencial de acelerar os progressos para as gerações futuras devem ser vistos como deveras benéficos para todos os países e regiões, à medida que os padrões de vida melhoram e o mundo inteiro se torna cada vez mais interdependente.

No tocante à Marinha do Brasil:

A Marinha do Brasil não está apenas construindo a Amazônia Azul, repensando o Atlântico Sul, a segurança nacional e todos os desafios que decorrem dessas questões: ela quer que o Brasil encontre novamente sua vocação marítima. Ela investe pesado na modernização e expansão de vários aspectos da Força Naval: a Força Submarina, que terá submarinos propulsados por energia nuclear; a Força de Superfície; e a Força Aeronaval, para poder desenvolver seu papel nacional e internacional no Atlântico Sul, ampliando, inclusive, sua cooperação com os países da África Ocidental para tal fim. Trata-se de apoiar os países africanos para que o Atlântico Sul seja realmente o "Oceano do Sul", sem que haja a presença do Norte - ou ao menos que essa presença não prejudique os interesses do Sul em geral e do Brasil, em particular (WIESEBRON, 2013, p. 125).

342 | Tensões Mundiais, Fortaleza, v. 21, N. 22, P. 323-346, 2016 
E, para se tornar possível alcançar tais objetivos, o Governo e o Congresso têm de dar o apoio necessário, em particular financeiramente, para que as Forças Armadas, e, no caso da Amazônia Azul, a Marinha e a Força Aérea estejam preparadas e com os equipamentos modernizados o suficiente para poder cuidar da soberania do país e ter o poder de dissuasão necessário. Tratase de "preservar a capacidade de um Estado costeiro fortalecer a Segurança Nacional" (BARBOSA JÚNIOR, 2007, p. 51). O Estado costeiro com uma Amazônia Azul certamente requer ainda mais atenção.

Em síntese, a partir de tudo que aqui foi apresentado e por meio de toda a pesquisa feita, foi possível compreender como o Brasil consegue alcançar um pragmatismo cada vez mais sofisticado, em que se torna factível a união das políticas diplomáticas, com as políticas de defesa, possibilitando, então, promover um desenvolvimento exponencial, que consegue transbordar inclusive para outros atores do Sul Global, que se beneficiam de um crescimento, que valoriza e prioriza a cooperação entre os Estados que, ainda que tardiamente, buscam um desenvolvimento efetivo e mais desprendido das heranças do velho pacto colonial, advindo das grandes potências europeias.

\section{REFERÊNCIAS}

ADESG (Associação dos Diplomados da Escola Superior de Guerra). A Amazônia Azul, 2011. Disponível em: <http://www. adesg.net.br/noticias/amazoniaazul>. Acesso em: 10 mai. 2016.

AGÊNCIA Nacional de Transportes Aquaviários. Anuário Estatístico Aquaviário, 2015. Disponível em: <http://www. antaq.gov.br/portal/Estatisticas_Anuarios.asp >. Acesso em: 11 dez. 2016.

AMORIM, C. O Brasil na Antártida. In: REUNIÃO CONSULTIVA DO TRATADO DA ANTÁRTIDA, 37., 2014, Brasília. Anais eletrônicos... Brasília: s/ed., 2014. Disponível em: <http:// www.defesa.gov.br/arquivos/2014/pronunciamentos/ministro/ abril/o_brasil_na_antartid a.pdf>. Acesso em: 23 fev. 2016. 
Murilo Gomes da Costa

BARBOSA, L. C. P.; PEREIRA, A. D. O Atlântico Sul no contexto das Relações Brasil-África. Revista Século XXI, Porto Alegre, v. 03, n. 01, p. 59-77, 2012.

BARBOSA JÚNIOR, I. A importância do Atlântico Sul para a segurança nacional e integração Regional. Revista da Escola Superior de Guerra, Rio de Janeiro, v. 23, n. 48, p. 43- 93, 2007.

BATTAGLINO, J. A reativação da IV Frota e o novo paradigma de controle global dos Estados Unidos. Política Externa, Brasília, v. 17, n. 04, p. 31-45, 2009.

BRASIL. Ministério da Defesa. Projetos estratégicos da Marinha, 2013. Disponível em: <http://www.defesa.gov.br/industria-dedefesa/paed/projetos-estrategicos/projetos-estrategicos-damarinha-do-brasil>. Acesso em: 24 nov. 2015.

CARVAlHO, R. de G. A Amazônia Azul. Defesanet, 04 mar. 2004. Disponível em: <http://www.defesanet.com.br/>. Acesso em: 21 mai. 2016

CNPQ. O Programa Antártico Brasileiro (PROANTAR), 2013. Disponível em: <http://www.cnpq.br/web/guest/apresentacaoproantar>. Acesso em: 12 jun. 2016.

COSTA, W. M. da. Projeção do Brasil no atlântico sul: geopolítica e estratégia. Revista USP, São Paulo, n. 95, p. 09-22, 2012.

CORRÊA, F. Atlântico Sul: e se não for um projeto político só da ZOPACAS?. Defesanet, 05 fev. 2013. Disponível em: <http:// www.defesanet.com.br/geopolitica/noticia/9566/Defesa-emDebate--Atlantico-Sul--e-se-nao-for-um-projeto-politico-so-daZOPACAS>. Acesso em: $10 \mathrm{dez} .2015$.

COUTO, J. A. C. A quem interessa a desmilitarização do Atlântico Sul?. Revista Marítima Brasileira, Rio de Janeiro, n. 119, s/p., 1999.

FERREIRA, F. R. G. O sistema do tratado da Antártica: evolução do regime e seu impacto na política externa brasileira. Brasília: Fundação Alexandre de Gusmão, 2009.

FÓRUM Defesa Brasil. Mapa de territórios britânicos no Atlântico Sul, 2015. Disponível em: <http://defesabrasil.com/ forum/>. Acesso em: $11 \mathrm{dez} .2016$. 
GODOY, R. Marinha renovará frota sob "pressão estratégica". O Estado de S. Paulo, 30 jan. 2011. Disponível em: <http://brasil. estadao.com.br/noticias/geral,marinha-renovara-frota-sobpressao-estrategica-imp-,672973>. Acesso em: 11 dez. 2016.

GOMES GUIMARÃES, B. A política brasileira para o Atlântico Sul: uma visão paradigmática. In: SEMINÁRIO INTERNACIONAL DE CIÊNCIA POLÍTICA, 1., 2015, Porto Alegre. Anais... Porto Alegre: UFRGS, 2015.

IISS (International Institute for Strategic Studies, The). The Military Balance 2013: the annual assessment of global military capabilities and defense economics. Londres: Routledge, 2013.

MACLAY, J. D. et alli. The Fourth Fleet: A Tool of U.S. Engagement in the Americas. Washington-DC: Center for Strategic and International Studies, 2009. p. 15. Disponível em: <http://www. voltairenet.org/IMG/pdf/The_Fourth_Fleet.pdf $>$. Acesso em: 24 jan. 2017.

MARINHA do Brasil. Programa Amazônia Azul, 2011. Disponível em <https://www.mar.mil.br/hotsites/amz_azul/html/ programa.html> Acesso em: 10 mai. 2016.

. A Presença Brasileira na Antártica, 2015. Disponível em: $\quad<$ https://www.mar.mil.br/dhn/dhn/hist_antartica.html $>$. Acesso em: 11 mai. 2016.

MATTOS, A. M. O Novo Direito do Mar. Rio de Janeiro: Renovar, 1996.

MIGUEL, S. L. C. Amazônia Azul: novas fronteiras. Rio de Janeiro: Escola Superior de Guerra, 2013.

NEVES, A. L. V. Atlântico Sul: projeção estratégica do Brasil para o século XXI. In: GHELLER, G. F.; GONZALES, S. L. de M.; MELLO, L. P. de (orgs.). Amazônia e Atlântico Sul: desafios e perspectivas para a defesa no Brasil. Brasília: IPEA; NEP, 2015

OLIVEIRA, G. Z. de; SILVA, I. L. da S.; PALUDO, J. A África no pós-Guerra Fria: geopolítica e novos atores. In: SPOHR, A. P.; MEDEIROS, K.; STADNIK, M. Relações Internacionais para Educadores: África em Foco. Porto Alegre: EdUFRGS, 2013. p. 161-183. 
Murilo Gomes da Costa

PENHA, E. A. Relações Brasil-África e Geopolítica do Atlântico Sul. Salvador: EdUFBA, 2011.

PORTO DE OLIVEIRA, A. A política africana da China. In: CONFERÊNCIA NACIONAL DE POLÍTICA EXTERNA E POLÍTICA INTERNACIONAL, 2., 2008, Brasília. Anais... Brasília: Funag, 2008. p. $13-32$.

RABElO, L. Conselho Sul Americano de Defesa. Revista Conjuntura Internacional, Belo Horizonte, s/v., s/n., p. 01-04, 2008.

REIS, R. G. G. dos. Atlântico Sul: Um desafio para o século XXI - As velhas ameaças se perpetuam nas "novas"?. In: ACIOLY, L.; MORAES, R. F. de (orgs.). Prospectiva, estratégias e cenários globais: visões de Atlântico Sul, África Lusófona, América do Sul e Amazônia. Brasília: IPEA, 2011.

ROMERO, C. A política externa da venezuela bolivariana: Plataforma Democrática. São Paulo; Rio de Janeiro: Fundação FHC; Centro Edelstein, 2010.

SARAIVA, J. F. S. África parceira do Brasil atlântico: As relações internacionais da África e do Brasil no início do século XXI. Belo Horizonte: Fino Traço, 2012.

UM DESAFIO atrás do outro. Petrobrás Magazine, ed. 56, 2016. Disponível em: <http://www.hotsitespetrobras.com.br/ petrobrasmagazine/Edicoes/Edicao56/pt/internas/pre-sal/>. Acesso em: 11 dez. 2016.

VERSCHAVE, F. De la Françafrique à la Mafiafrique. Bruxelas: Édition Tribord, 2004.

WIESEBRON, M. Amazônia Azul: Pensando A Defesa Do Território Marítimo Brasileiro. Austral: Revista Brasileira de Estratégia e Relações Internacionais, Porto Alegre, v. 02, n. 03, p. 107-131, 2013. 